than seven hundred implements belonging to this early phase of the American stone age, it is stated in a communication issued by Science Service of Washington, D.C., have been discovered, among them being a number of new types. The variety in type of the implements continues to be a marked feature of the site. A find of considerable importance is recorded, which corroborates conclusively previous evidence for the contemporaneous existence in this region of man and an extinct fauna. This is the discovery of the vertebra of a bison, in which is still embedded the stone point of the lance or dart with which it had been struck by the primitive hunter. The vertebra belongs to the extinct form of bison already found here and elsewhere in association with the artefacts of Folsom man. It has already been pointed out (see Nature, loc. cit.) that the Lindenmeier site gives in situ, for the first time, a view of the Folsom implement as forming part of a cultural complex, and thus justifies the use of the term 'Folsom culture'. To this complex must now be added an art form, the first known in this early phase of culture, which appears on a flat bone disc showing decorative marks around the edge. No information is as yet available on the further investigation of the stratigraphy of the site and its relation to adjacent gravels, from which it is hoped to attempt a dating of this centre of the Folsom culture.

\section{A Thames Barrage}

WITH the arrestive title of "Dam the Thames", a brochure has been issued by the Thames Barrage Association advocating the scheme put forward a short time back in a paper read before the London Society by Mr. J. H. O. Bunge, who is honorary secretary of the Association since formed to promote the impounding of a large section of the Thames estuary. The original proposal is modified in respect of the position of the proposed barrage, which it is now suggested should be located at Woolwich. The cost of the scheme is estimated at about $4 \frac{1}{2}$ millions sterling, but, as has been abundantly demonstrated in other projects of corresponding magnitude, this figure must be received with a certain amount of reserve. According to the pamphlet, the resultant savings, enumerated under eighteen categories, would aggregate about $£ 611,000$ per annum, representing a capitalised value of 20 millions sterling. Some of the items of this calculation seem to be based on data of a rather uncertain character, so that here, too, the estimate must be considered more or less speculative. An official, public inquiry into the merits of the scheme is urged on the grounds that the scheme, if carried out, would be of great advantage to navigation in maintaining a permanent water level in the river and so enabling craft to move freely, and independently of tidal restrictions, in and out of the docks, and to and from the riverside wharves above Woolwich; in excluding sewage effluent at present brought up-river by tidal flow from the outfalls at Crossness and Barking; and in avoiding the risk of flooding at times of abnormally high tides. Various other benefits are categorically enumerated.
Alxноugh an inquiry, which would involve some time and expense, might resolve some of the problems connected with the formulation of the barrage scheme, it must be borne in mind that an enterprise of this magnitude cannot be embarked upon without a considerable degree of risk to important interests, however propitious the general circumstances may appear to be. It will be recalled that a cognate scheme, the Severn Barrage, was definitely promoted by the Government and became the subject of a prolonged and searching inquiry by experts; but the findings of the committee, although favourable, have not, so far, resulted in the materialisation of the project, which, in the language of the Ministry of Transport, was to bring "within the reach of all classes of the community the blessings of light, purity and power". It is also to be noted that the Port of London Authority has had the present proposals before it, and has not accorded them its support. The reasons have not been stated, but it is clear that they were such as to carry preponderant weight with those most intimately concerned with the great shipping and commercial interests of the port. This does not, in itself, suffice to condemn the project; but it rather discounts the florid assertions of the pro. moters, and justifies an attitude of caution and reserve.

\section{Ice Accretion on Aircraft}

Lecturing before the Royal Aeronautical Society on November 4, Mr. Lockspeiser, of the Royal Aircraft Establishment, Farnborough, described experiments upon this subject which have led to the recommendation of a certain method of combating this. It consists of forcing ethylene-glycol through a porous leather strip which can be attached to, or form part of, those surfaces upon which ice appears to form. This presents the greatest danger when on the leading edges of the various lifting surfaces and the airscrew. In such cases it not only adds to the weight to be carried but it also reduces the efficiency by changing the shape, and in the case of the propeller it causes out of balance forces that necessitate slowing it down with still further loss. The action of the ethylene-glycol is to prevent the ice from adhering to the surface. Mr. Lockspeiser referred to thermal methods for prevention of ice formation, and mechanical methods for dislodging it, but said that neither of these has the simplicity and the general application to all cases of the evaporation method. Thermal methods, using the engine heat to warm the wing surfaces, may become more attractive upon larger thick-winged monoplanes, where the 'plumbing' difficulties would be less. Mechanical methods of dislodging the ice from the planes have been used for some time in the United States, but are not applicable to the propeller. Experiments are now being made with devices similar to the British ones, using rubber sheathing and oil. The experiments described were undertaken originally for R.A.F. requirements; but the question was considered to be so vital to civil aviation, that the results have been made public and the device is to be marketed by the Dunlop Company. 